\title{
Determination of the Value of the Damage Function in 1050A Aluminium Alloy
}

\author{
Patrycja Walczuk-Gągała', Zbigniew Pater', Łukasz Wójcik' \\ 1 Department of Computer Modelling and Metal Forming Technologies, Faculty of Mechanical Engineering, \\ Lublin Univeristy of Technology, Nabystrzycka 36, 20-618 Lublin, Poland \\ * Corresponding author's e-mail: p.walczuk@pollub.pl
}

\begin{abstract}
The article presents the problem of material cracking in metal forming processes. The authors describe and compare the values of damage obtained in classic tensile and compression tests as well as rotational compression of $1050 \mathrm{~A}$ aluminium alloy in cold working conditions. The presented research methodology contains experimental tests as well as a numerical simulation conducted in Simufact.Forming v.15. An analysis of the damage values was calculated according to the normalised Cockcroft-Latham criterion. The research conducted showed that the damage value in the rotational compression test is greater than the values obtained by the means of other tests.
\end{abstract}

Keywords: material fracture, critical value of damage, 1050A aluminium alloy

\section{INTRODUCTION}

The main issue in the process of metal forming is ductile fracture. It is the key parameter hindering the deformability of the material [1]. The accuracy of predicting the surface and inner cracks in the processes of metal working has a significant influence on the technology of element design. Based on numerous hypotheses, various ductile fracture criteria were proposed both empirically and theoretically. The empiric criteria allow one to assess the possibilities of material fracture on the basis of the state of stress, regardless of the changes to the material structure [2]. Ductile fracture in solids depends on the full load history. Typical criteria for ductile fracture at room temperature are usually based on the combination of stress and strain [3]. These criteria can only be applied when the critical values of the damage criterion are known. Fracture occurs, when the following condition is fulfilled $[4,5]$ :

- Frudenthal criterion

$$
\int_{0}^{\varepsilon_{f}(t)} \bar{\sigma} d \varepsilon \geq C
$$

- Cockcroft-Latham criterion

$$
\int_{0}^{\varepsilon_{f}(t)} \sigma_{\max } d \varepsilon \geq C
$$

- Normalized Cockcroft-Latham criterion

$$
\int_{0}^{\varepsilon_{f}(t)} \frac{\sigma_{\max }}{\sigma_{H}} d \varepsilon \geq C
$$

- Brozzo criterion

$$
\int_{0}^{\varepsilon_{f(t)}} \frac{2 \sigma_{\max }}{3\left(\sigma_{\max }-\sigma_{H}\right)} d \varepsilon \geq C
$$

- Norris criterion

$$
\int_{0}^{\varepsilon_{f(t)}} \frac{1}{\left(1-C * \sigma_{H}\right)} d \varepsilon \geq C
$$

where: $\sigma_{H}-$ mean stress,

$\sigma_{\max }-$ maximum principal stress,

$\bar{\sigma}-$ effective stress, $\varepsilon$ - effective strain,

$\varepsilon_{f}(t)$ - value of strain at which the fracture occurred,

$C$ - material constant.

Determining the critical value $\mathrm{C}$ of the damage function allows one to accurately estimate the moment of fracture when the stress state of 
the analysed process is similar to the stress state occurring during the calibrating test. The process of fracture is difficult to prognosticate in the case of materials with plastic properties in the case of constant and variable load. As far as constant load is concerned, the tests applied to determine the boundary conditions of the damage functions are: tensile, compression and torsion tests [9]. In the case of varied load acting on the workpiece in the process of plastic forming, determining the aforementioned value may pose problems [6].

A new method, allowing one to determine the value of damage during the cyclically changing load, was developed in Lublin University of Technology $[7,8]$. It is known as rotary compression in a channel. Scheme of the test was presented in Figure 1. During this test a sample with the diameter $d_{0}$ and length $l_{0}$ is placed on the nether, flat tool at the distance $s$ from the end of the tool. The upper tool is set in motion at the velocity $v$, whereas the nether tool remains static. The distance between two tools equals $2 h$ and is smaller than the diameter of the sample. In the front part of the upper tool an undercut at the angle $\gamma$, which allows the sample to be introduced between the tools. During rotary compression the material in the axis is subjected to cyclic compressive - tensile stresses acting in the radial direction, which results is ductile fracture. It is therefore possible to determine the plastic properties of the material for a significantly wider range of strain than before.

\section{MATERIAL AND METHODS}

The material used in the research was 1050A aluminium alloy. Its chemical composition was presented in Table 1.

The research comprised of classic tensile and compression tests of formed samples and aimed to obtain reference material for the new test of rotary compression. The shape and dimensions of the samples are shown in Figure 2 and 3.

In order to conduct the aforementioned tests a testing machine Instron 1000HDX was used. A measuring stand allowed the movement of the slide and force in the time function. The speed of the tools was equal $5 \mathrm{~mm} / \mathrm{min}$. For the rotary compression test cylindrical samples with the initial dimensions $\varnothing 30 \times 60 \mathrm{~mm}$ were used. The strain rate remained constant $\delta=\frac{d_{0}}{d}=1,07$. The workpiece was rolled using a cross-wedge rolling mill (Fig. 4) located in the Department of Computer Modelling and Metal Forming Technologies in Lublin University of Technology. This rolling mill enables one to use flat tools up to $1000 \mathrm{mmm}$ long. Figures 5-6 present flat tools mounted in the working area of the rolling mill

The upper flat tool moved at $300 \mathrm{~mm} / \mathrm{s}$, whereas the nether tool remained fixed. The rotary compression test was performed with different values of the path $s$ in order to determine the value at which facture would occur. The experimental tests were conducted at $20^{\circ} \mathrm{C}$.
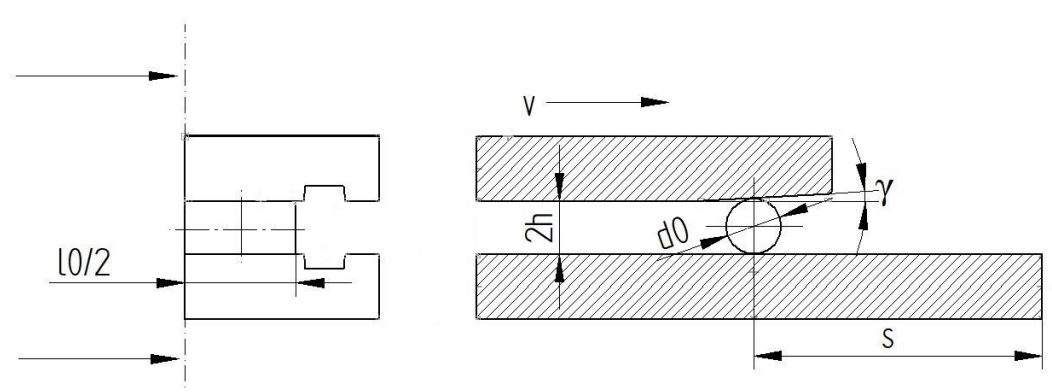

Figure 1. Scheme of rotary compression with flat tools

Table 1. Chemical composition of 1050A aluminium alloy

\begin{tabular}{|c|c|c|c|c|c|c|c|c|}
\hline $\mathrm{Al}$ & $\mathrm{Fe}$ & $\mathrm{Si}$ & $\mathrm{Zn}$ & $\mathrm{Ti}$ & $\mathrm{Mg}$ & $\mathrm{Mn}$ & $\mathrm{Cu}$ & Other \\
\hline $\min 99.50$ & $\max .0 .40 \%$ & $\max .0 .25 \%$ & $\max .0 .07 \%$ & $\max .0 .05 \%$ & $\max .0 .05 \%$ & $\max .0 .05 \%$ & $\max .0 .05 \%$ & $\begin{array}{c}\max . \\
0.03 \%\end{array}$ \\
\hline
\end{tabular}


a)

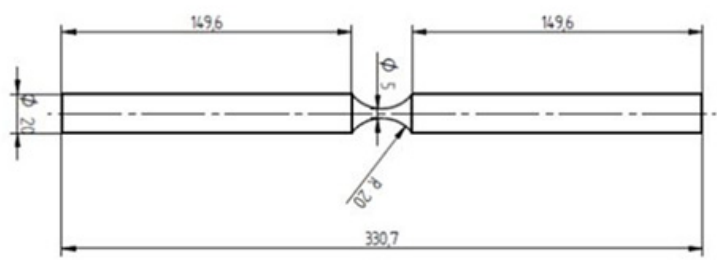

b)

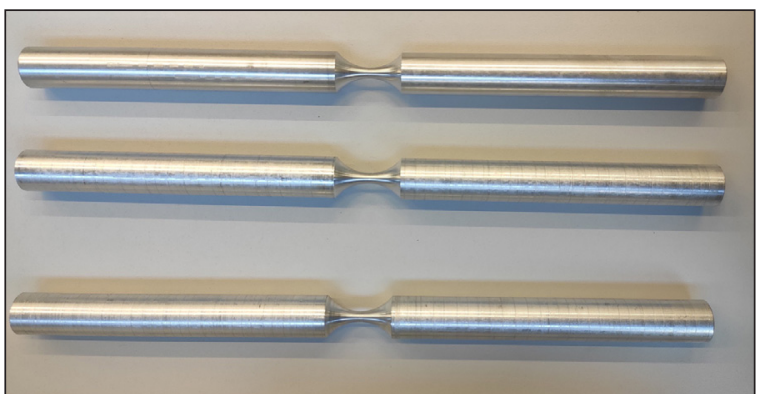

Figure 2. Samples used in the tensile test: a) shape and dimensions, b) samples made of 1050A aluminium alloy

a)

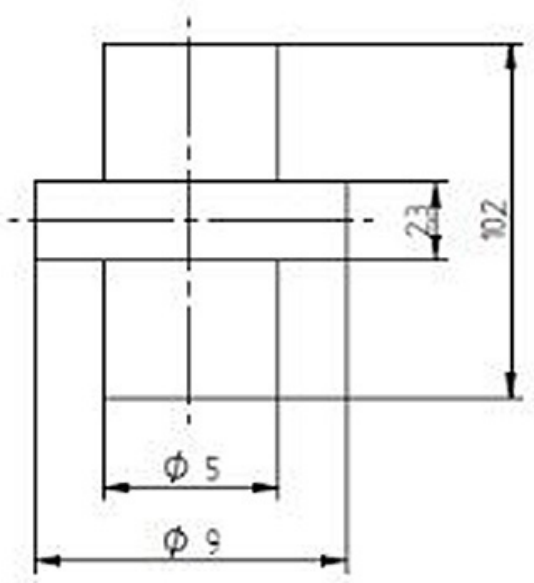

b)

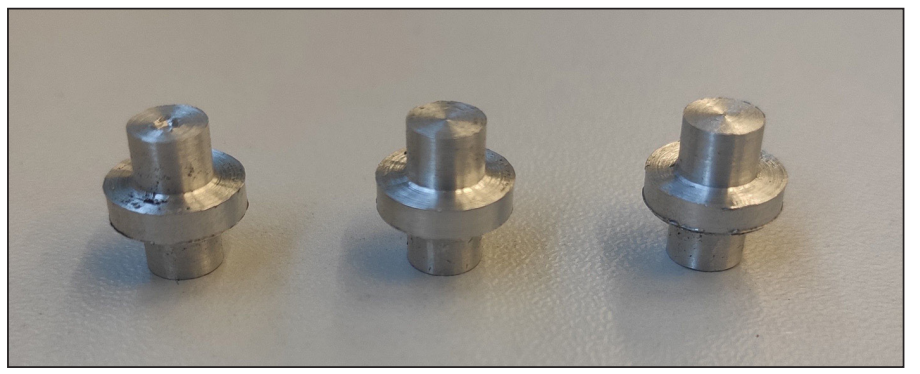

Figure 3. Samples used in compression test: a) shape and dimensions, b) samples made of 1050A aluminium alloy

\section{NUMERICAL ANALYSIS}

Figure 7 shows geometrical models of the tensile, compression and rotary compression tests. The models were created using Simufact. Forming v.15. In the tensile test the geometry of the billet material was modified using Solid Edge software, which allowed one to stretch the sample vertically, while the upper ring moved at $0.083 \mathrm{~mm} / \mathrm{s}$, whereas the nether one remained fixed. The compression test was conducted at the

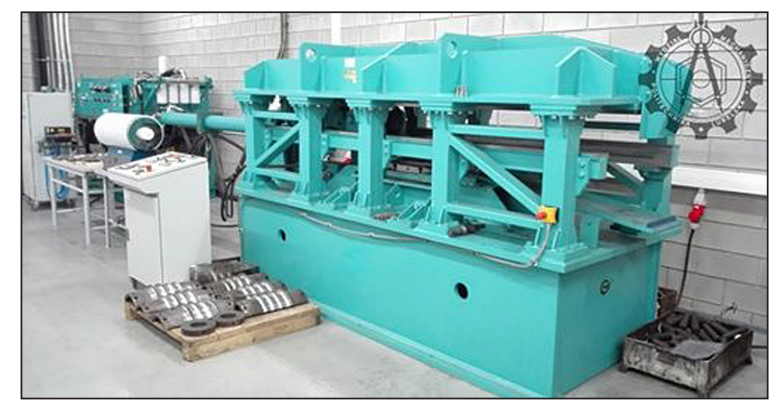

Figure 4. Flat-wedge rolling mill used in experimental testing upper tool speed equal $0.083 \mathrm{~mm} / \mathrm{s}$. The nether tool was fixed. In the rotary compression test the tools and the billet had plane of symmetry. The upper tool moved at $300 \mathrm{~mm} / \mathrm{s}$, whereas the nether one remained fixed. Friction factor for the surface detail - tool was equal 0.9 , whereas the heat transfer coefficient for detail - tool equalled $20000 \mathrm{~W} / \mathrm{m}^{2} \cdot \mathrm{K}$. Billet temperature was $20^{\circ} \mathrm{C}$, whereas the dimensions of the billets were assumed to be similar to the ones from experimental testing. In the calculations the material model of 1050A aluminium alloy was used, downloaded

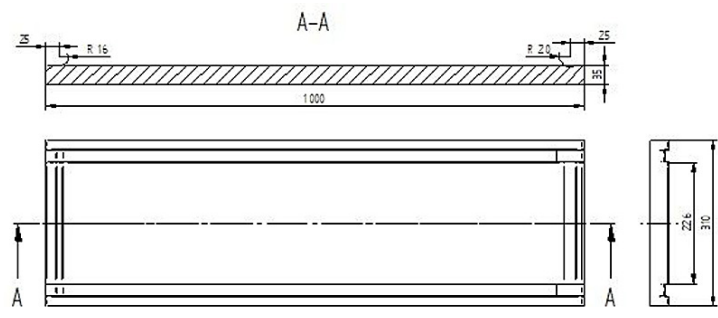

Figure 5. Nether tool segment (fixed jaw) used in the rotary compression test 
from the Simufact.Forming data library and described with the following equation:

$$
\begin{gathered}
\sigma_{F}=161.437 \cdot e^{(-0.00186541 \cdot T)} . \\
\cdot \varphi^{(-3.95844 e-5 \cdot T+0.178173)} . \\
\cdot e^{\left(\frac{3.87661 e-5 \cdot T+(-0.0122739)}{\varphi}\right)} . \\
\cdot \dot{\varphi}^{(0.000185313 \cdot T+0.0221668)}
\end{gathered}
$$

where: $\sigma_{F}-$ flow stress [MPa],

$T$ - temperature $\left[{ }^{\circ} \mathrm{C}\right]$,

$\varphi-\operatorname{strain}[-]$,

$\dot{\varphi}-$ strain rate $[1 / \mathrm{s}]$.

Based on the results obtained in experimental testing an analysis, in regard to force and the value of damage, an analysis was conducted. The samples after tests are presented in Figure 8. In the samples subjected to tensile a crack occurred in the middle of the necking. In samples subjected to compression no cracks were observed on the side surfaces.

In the majority of samples subjected to rotary compression no cracks were observed on the surface. For this reason $\mathrm{x}$-ray photograph were taken using North Star Imaging programme. Figure 9 presents the results of the examination of the samples shown in fig. $8 \mathrm{c}$ along with the length of the

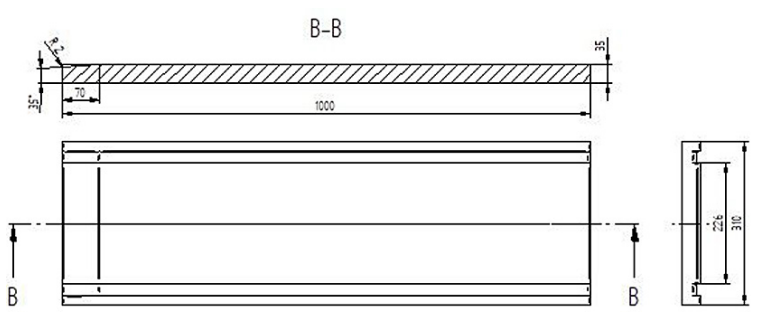

Figure 6. Upper tool segment (movable jaw) used in the rotary compression test

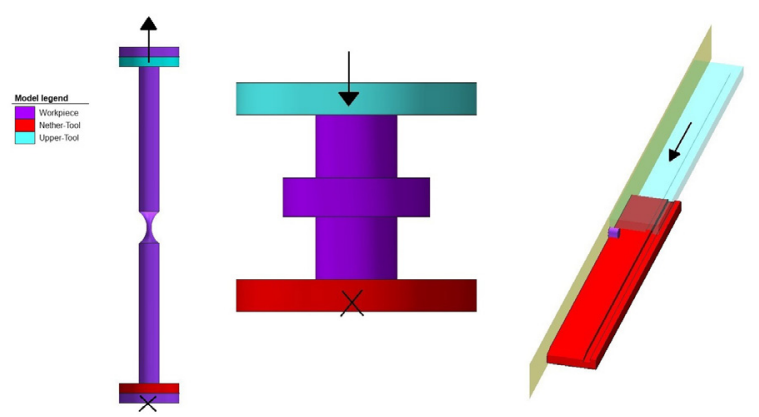

Figure 7. Models of the performed tests, created in Simufact.Forming: a) tensile, b) compression, c) rotary compressionRESULTS cracks. Their length increases along with the length of the forming path.

During the experimental tests and numerical analyses the values of forming forces were registered (Fig. 10). It can be observed that force distributions were similar for all of the performed tests. In the case of the rotary compression test the experimental analysis showed higher values of force at the end of the process than numerical

a)

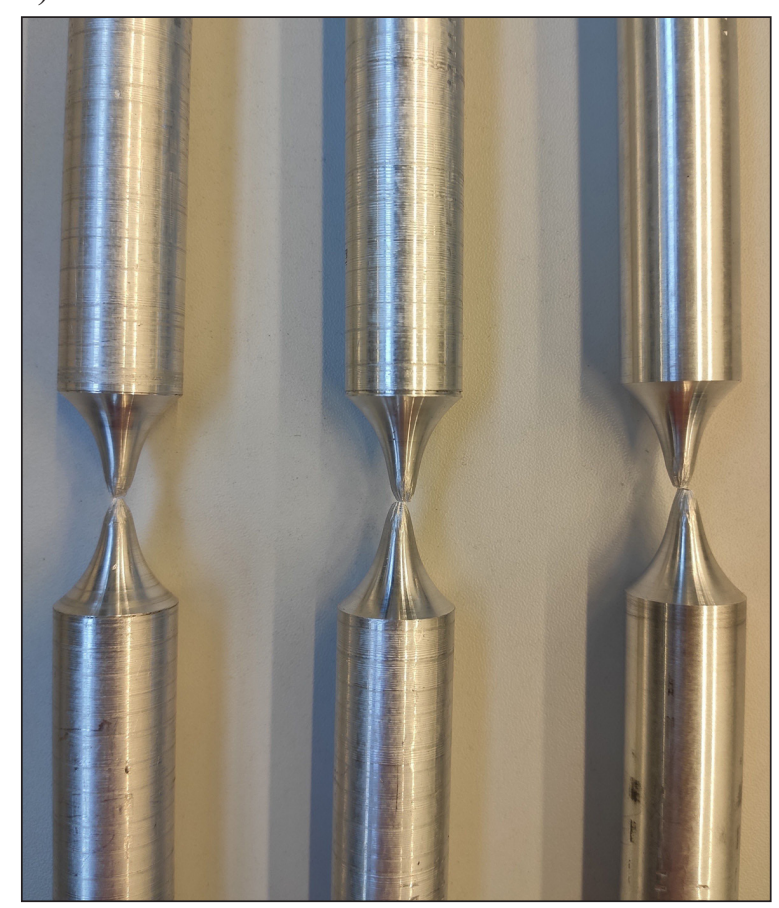

b)

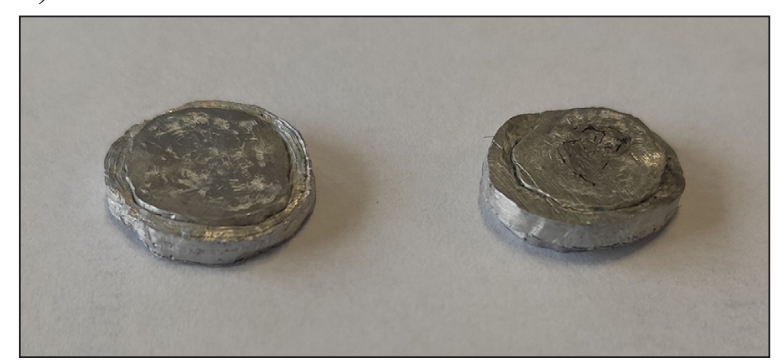

c)

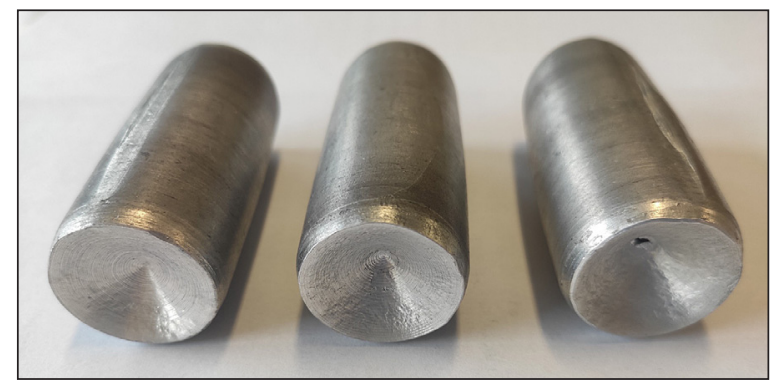

Figure 8. Elements after the tests: a) tensile, b) compression, c) rotary compression (forming path, respectively from the left $s=700,800,900 \mathrm{~mm}$ ) 
a)

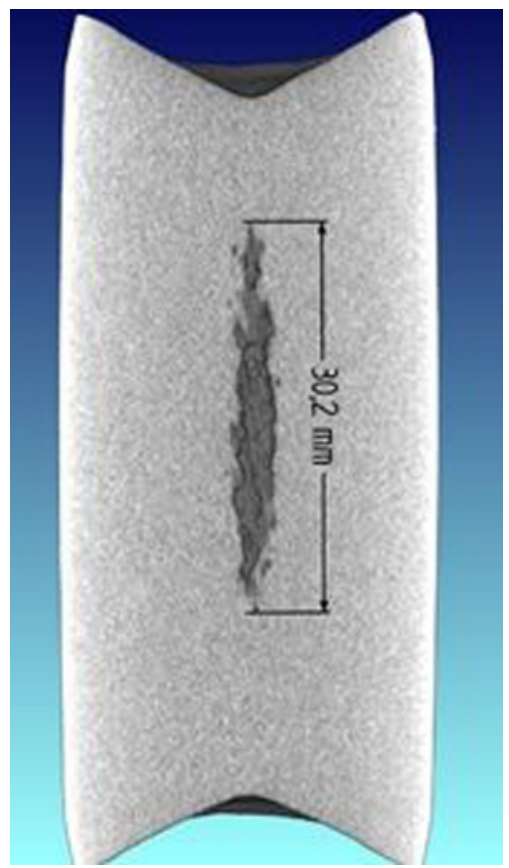

b)

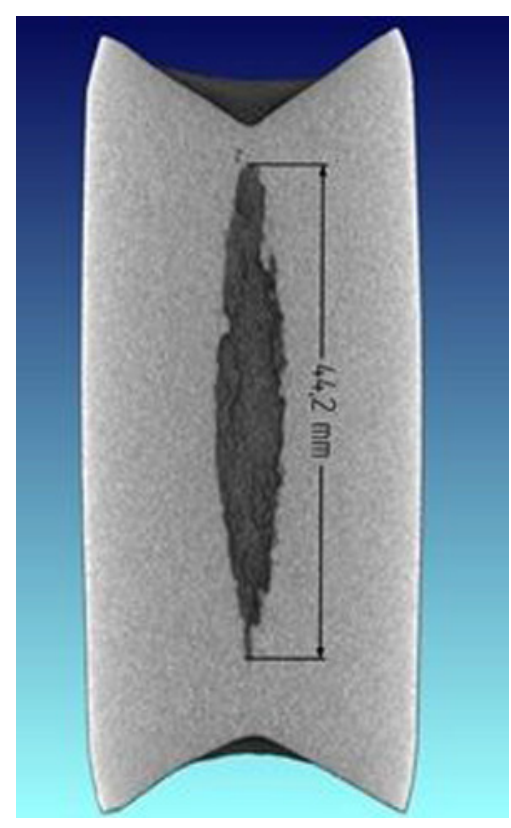

c)

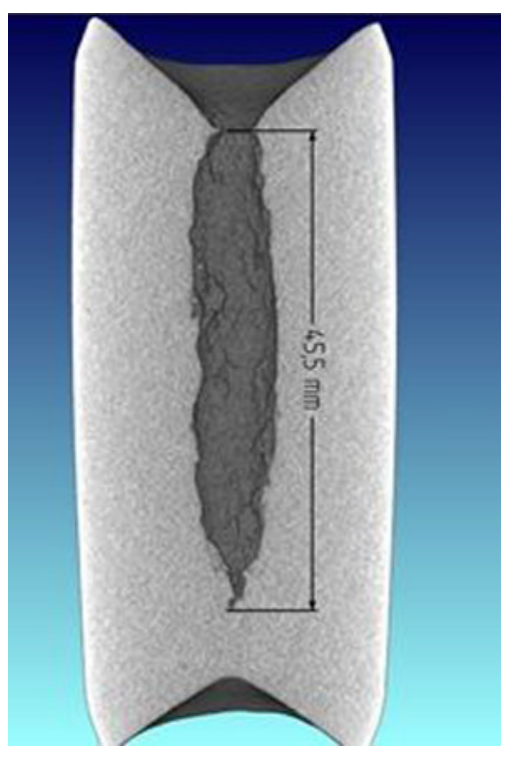

Figure 9. Inner scans of the samples subjected to rotary compression, forming path, respectively from the left $s=700,800,900 \mathrm{~mm}$

analysis, which may be caused by a cracking resulting in ovalisation of the sample.

Figure 11 shows the distribution of Cockcroft - Latham integral in the sample subjected to tensile test. The greatest values occur in the center of the necking, where the material cohesion was disrupted. The value of the integral in this point in the moment of cracking was assumed to be the limit value. Three sensors, located at $2.4 \mathrm{~mm}$ from each other were placed in the axis of the element in its narrowest point (necking). The maximum value of the damage function occurred in the center of the cross-section (points 1 and 2). The greatest value determining the cracking of the material in the tensile test at the room temperature and at the tensile rate $5 \mathrm{~mm} / \mathrm{min}$ was assumed to be 0.733 .

No fracture was observed over the course the upsetting test. The highest value of the damage function was noted in the collar part of the sample (Fig. 12). For this reason, three sensors placed every $1 \mathrm{~mm}$ from each other were located along the edge. Maximum value of the damage function occurred in the middle of the edge (point 2). The damage function in the test was 0.384 .

Figure 13 presents the distribution of the damage function in the sample after rotary compression. The formula of the function is ring-shaped with its highest values occurring in the axial area of the workpiece, where the fracture is most likely to occur. The value of the damage function in the test is significantly higher than the value obtained in standard tensile and compression tests conducted as means of comparative analysis.

In the element subjected to rotary compression fracture occurred along the axis of the sample. For this reason, the damage value occurring in this area was assumed to be the limit value.

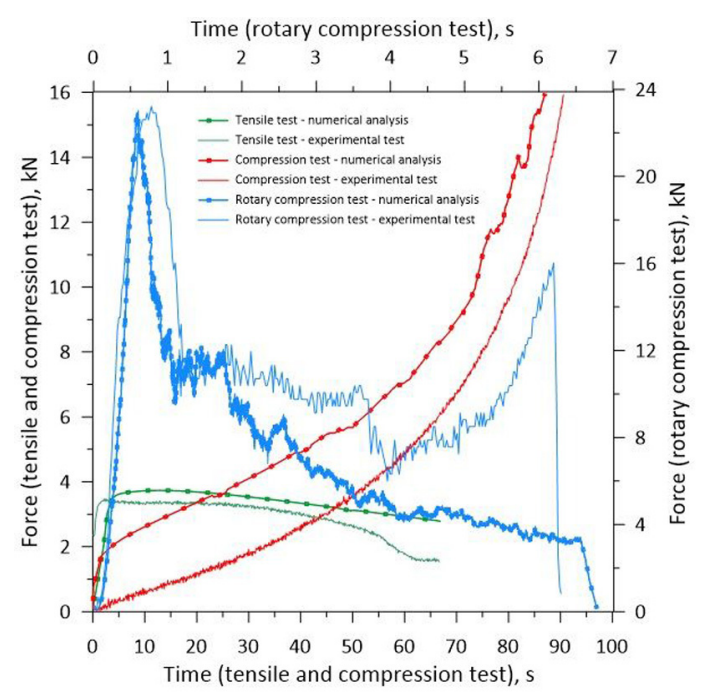

Figure 10. Change to the force values during the experimental testingThe assessment of the damage value was made on the basis of normalized Cockcroft

- Latham criterion, which is the most commonly used in programmes for numerical simulation. 


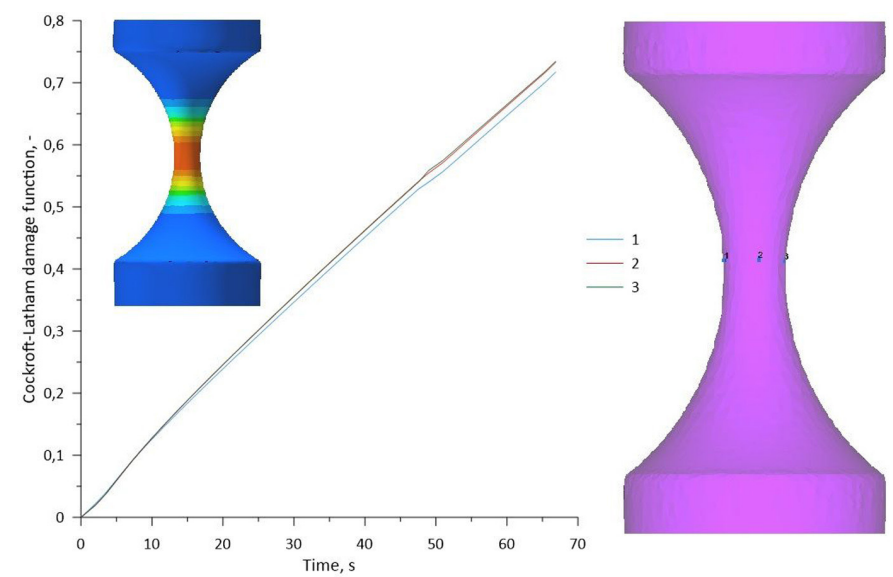

Figure 11. Change to the value of the damage function in the sample subjected to tensile test, calculated in accordance with Cockcroft - Latham criterion, in the axis of the compressed sample

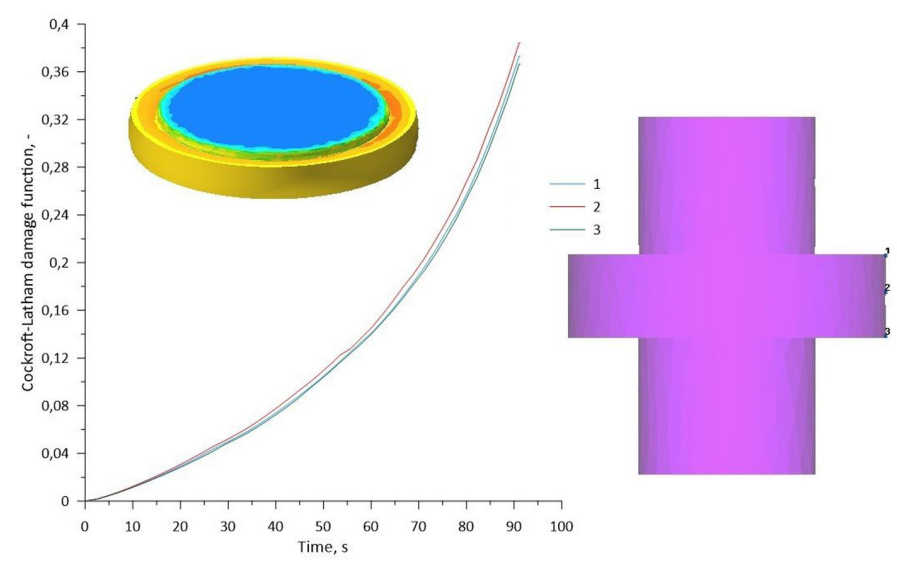

Figure 12. Change to the value of the damage function in the sample subjected to compression, calculated in accordance to Cockcroft - Latham criterion in the axis of the compressed sample

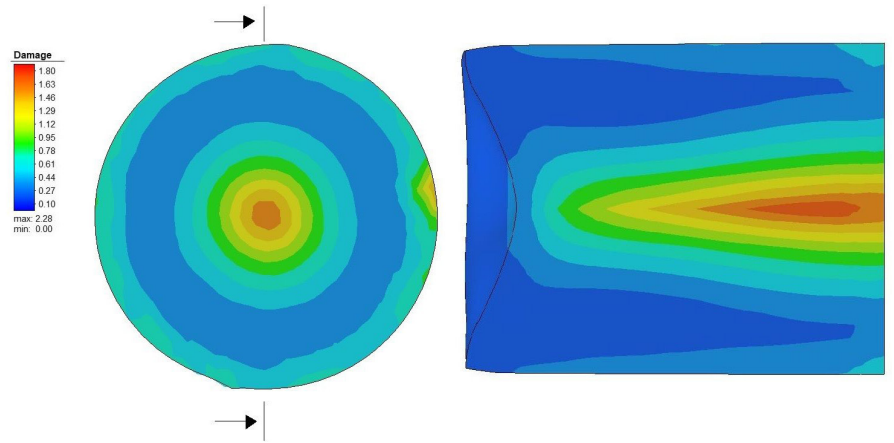

Figure 13. Distribution of the damage function in the rotary compression test, the sample formed at the path $s=700 \mathrm{~mm}$

In order to accurately determine the critical values of the damage function 20 sensors (placed by $1.5 \mathrm{~mm}$ ) were located in the axis of the sample. The sensors aimed to monitor the value of the normalized Cockcroft-Latham criterion. Sensor 1 was placed on the side surface of the sample, whereas sensor 20 in its centre. Figure 14 presents the distribution of the damage function. 

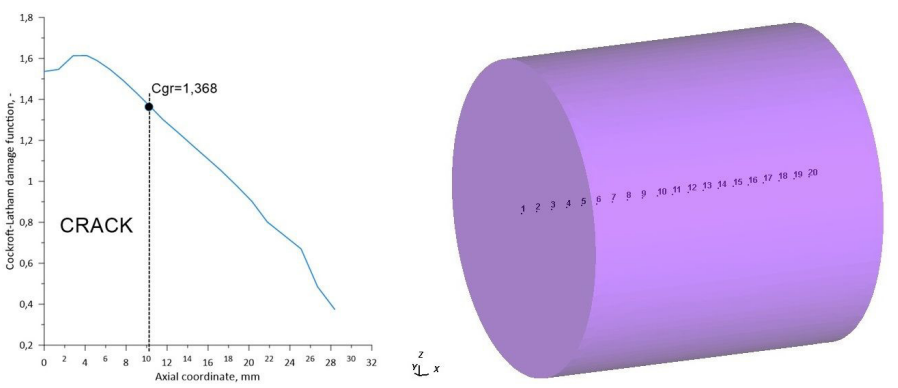

Figure 14. Change to the damage function, calculated in accordance to the Cockcroft - Latham criterion in the axis of the compressed sample

The maximum values of the function obtained in each point are not similar and decrease along with he increase of the distance from the center of the sample. Average length of the crack (for $s=700 \mathrm{~mm}$ ) equalled $30.177 \mathrm{~mm}$. Assuming that the crack is located symmetrically in the workpiece, the limit value is 1.368 in point 11 . This value is 3.56 times greater than the one obtained in the upsetting test and 1.86 times greter than in the tensile test.

\section{CONCLUSION}

The article presents the methodology and test results aiming to determine the values of the damage function according to Cockcroft - Latham for cold-formed 1050A aluminium alloy. In the research the damage values for the classic tensile and compression tests as well as rotary compression were analysed. On the basis of these results, the following conclusions were drawn:

- The rotary compression test may be used to determine the value of the damage function,

- The distribution of the damage function is ring-shaped in the sample subjected to rotary compression and therefore the highest values occur in the axial area of the sample,

- The value of the damage function in the rotary compression test is 3.56 times greater than the value obtained in the upsetting test and 1.86 times greater than in the tensile test,

- The greatest value of force was observed in the rotary compression rest $(23.22 \mathrm{kN})$, the smallest in the tensile test $(3.4 \mathrm{kN})$

- During the rotary compression test the lenght of the crack depends on the lenght of the forming path.

\section{Acknowledgments}

The research has been conducted under the project No. 2017/25/B/ST8/00294 financed by the National Science Centre, Poland.

\section{REFERENCES}

1. Anderson T.L. Fracture Mechanics: Fundamentals and Applications. CRC Press, 2005.

2. Bulzak T., Pater Z., Tomczak J., Wójcik Ł. A rotary compression test for determining the critical value of the Cockroft-Latham criterion for R260 steel. International Journal of Damage Mechanics, 28(10), 2019, 1-13.

3. Li h., Fu M.W., Lu J., Yang H. Ductile fracture: Experiments and computations. International Journal of Plasticity, 27(2), 2011, 147-180.

4. Ozturk F., Lee D. A new methodology for ductile fracture criteria to predict the forming limits. Journal of Materials Engineering and Performance, 62(2), 2007, 224-228.

5. Pater Z., Samołyk G. Podstawy teorii i analizy obróbki plastycznej metali. Wydawnictwo Politechniki Lubelskiej, 2011.

6. Pater Z., Tomczak J., Bulzak T., Zniszczyński A. The problem of material fracture prediction in cross rolling processess. Advances in Science and Technology Research Journal, 12(4), 2018a, 184-189.

7. Pater Z. Sposób wyznaczania właściwości plastycznych materiałów metodą obciskania obrotowego narzędziami płaskimi. Patent RP No 220786, 2014.

8. Pater Z. Sposób wyznaczania własności plastycznych materiałów metodą obciskania obrotowego dwoma walcami. Patent RP No 220753, 2015.

9. Sebek F. Ductile fracture criteria in multiaxial loading - theory, experiments and application. Doctoral Thesis. Brno Univeristy of Technology, 2016. 